\title{
The importance and ways of exploring the entire chest before and after cardiac surgery: Chest radiography, lung ultrasonography, and computed tomography
}

\author{
Massimiliano Cantinotti, MD
}

\footnotetext{
From the Pediatric Cardiology and GUCH Unit, Fondazione CNR-Regione Toscana G. Monasterio, Massa and Pisa, Italy.

Disclosures: Author has nothing to disclose with regard to commercial support.

Received for publication Jan 6, 2018; accepted for publication Jan 12, 2018; available ahead of print March 3, 2018.

Address for reprints: Massimiliano Cantinotti, MD, Pediatric Cardiology and GUCH Unit, Fondazione CNRRegione Toscana G. Monasterio, Via Aurelia Sud, 54100 Massa, Italy (E-mail: cantinotti@ftgm.it).

J Thorac Cardiovasc Surg 2018;155:2041-2 $0022-5223 / \$ 36.00$

Copyright (C) 2018 by The American Association for Thoracic Surgery https://doi.org/10.1016/j.jtcvs.2018.01.032
}

Evaluation of the lungs and the entire chest is of crucial importance before and after cardiac surgery, particularly in terms of pulmonary diseases; relationships of the heart, aorta, and great vessels with other organs; and the extent and degree of calcifications. ${ }^{1}$ In this issue of the Journal, den Harder and colleagues ${ }^{1}$ evaluate the frequency of abnormalities on preoperative chest radiographs before cardiac surgery and explore their clinical implications. They demonstrate how chest radiography (CXR) usually does not affect the surgical planning; in some cases, however, abnormal findings may have important clinical consequences.

CXR is widely used for broad and fast evaluation of chest diseases, and it is routinely performed as the first imaging technique before and after cardiac surgery. ${ }^{1,2}$ Alternatives to CXR are gaining consensus, however, in both the preoperative and postoperative settings. Preoperatively, it has been suggested that CXR may be replaced by lowradiation dose computed tomography (CT). ${ }^{3,4} \mathrm{CT}$ is the criterion standard for chest imaging; it allows accurate evaluation and quantification of calcifications and provides a 3-dimensional reconstruction of the heart, the great vessels, and their relationship in the chest. ${ }^{3,4} \mathrm{CT}$ is expensive, however, and it carries risks related to transportation of patients in critical condition to the radiology department ${ }^{2}$ and radiation exposure (particularly in children). ${ }^{2}$ It has been proved for reoperative surgery that CT use for surgical planning may reduce intensive care unit stays, blood transfusions, and perioperative myocardial infarction. ${ }^{3}$ Whether CT should be limited to difficult cases or extended to all adult patients undergoing cardiac surgery, however, ${ }^{1,3,4}$ remains controversial.

In the postoperative period, CXR is routinely performed to evaluated drainage and catheter position and to monitor pulmonary complications. The excessive repetition of CXR examinations, however, has been criticized. ${ }^{1,2}$ In

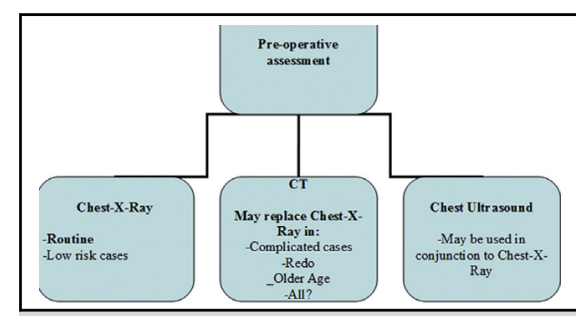

Flow chart on use of chest radiography, $\mathrm{CT}$, and chest ultrasonography in cardiac surgery.

Central Message

Chest radiography is a fundamental tool in cardiac surgery, but it may be replaced by CT preoperatively, at least in selected cases, and by LUS to monitor common postoperative pulmonary complications.

See Article page 2035.

this setting, the potential role of lung ultrasonography (LUS) merits attention. LUS is gaining consensus as an easy, accurate, fast, cheap, and radiation-free tool for the diagnosis of pulmonary diseases in acute settings. ${ }^{2}$ LUS has proved its accuracy in diagnosis of all common pulmonary postoperative complications, including pleural effusion, atelectasis, pneumothorax, and pneumonia. ${ }^{2}$ Relative to CXR, LUS has the capacity for differential diagnosis among these complications (eg, pleural effusion vs atelectasis or consolidation). ${ }^{1}$ Furthermore, LUS has shown superior sensitivity and similar specificity to CXR for the detection of pneumothorax, ${ }^{5}$ and it was found to be superior to both CXR and CT in the classification of pneumothorax size. ${ }^{5}$ The use of LUS for the evaluation of lung water content has been extensively studied in adults with heart failure. ${ }^{6,7}$ Its application in cardiac surgery may help to modulate diuretic therapy and also provide prognostic information, ${ }^{8,9}$ although evidence remains limited. Chest ultrasonography (eg, the evaluation of the entire chest as well as the lungs) furthermore allows exploration of the retrosternal area, a zone often difficult to image with conventional echocardiography and one where postsurgical clots (even compressing the heart) may be detached. $^{10,11}$

In summary, CXR continues to hold a great diagnostic utility in cardiac surgery; however, low-radiation dose CT 

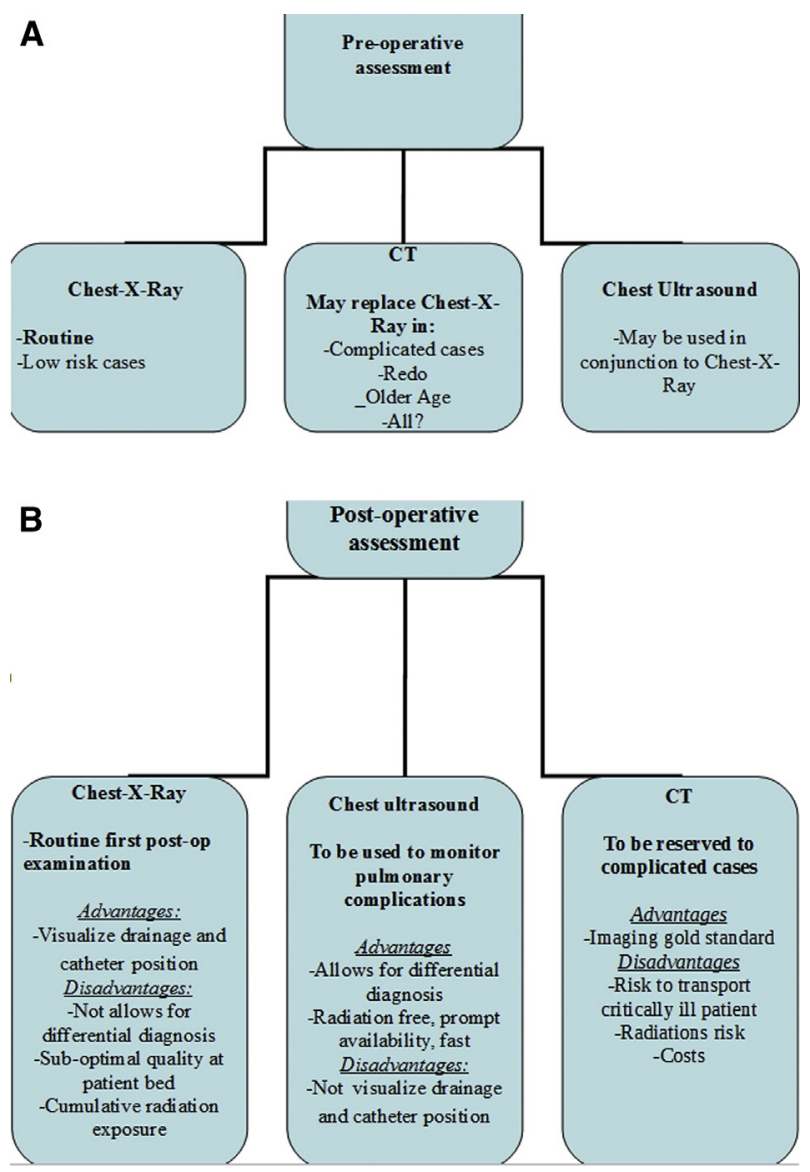

FIGURE 1. A proposed flow chart for the potential use of chest radiography (Chest-X-Ray), computed tomography $(C T)$, and chest ultrasonography before (A) and after (B) cardiac surgery. scan (preoperatively) and chest ultrasonography (postoperatively) are valid complementary or alternative examinations (Figure 1).

\section{References}

1. den Harder AM, de Heer LM, de Jong PA, Suyker WJ, Leiner T, Budde RP. Frequency of abnormal findings on routine chest radiography before cardiac surgery. J Thorac Cardiovasc Surg. 2018;155:2035-40.

2. Cantinotti M, Giordano R, Volpicelli G, Kutty S, Murzi B, Assanta N, et al. Lung ultrasound in adult and paediatric cardiac surgery: is it time for routine use? Interact Cardiovasc Thorac Surg. 2016;22:208-15.

3. Goldstein MA, Roy SK, Hebsur S, Maluenda G, Weissman G, Weigold G, et al. Relationship between routine multi-detector cardiac computed tomographic angiography prior to reoperative cardiac surgery, length of stay, and hospital charges. Int J Cardiovasc Imaging. 2013;29:709-17.

4. den Harder AM, de Heer LM, Maurovich-Horvat P, Merkely B, de Jong PA, Das M, et al. Ultra low-dose chest CT with iterative reconstructions as an alternative to conventional chest $\mathrm{x}$-ray prior to heart surgery (CRICKET study): rationale and design of a multicenter randomized trial. J Cardiovasc Comput Tomogr. 2016;10:242-5.

5. Volpicelli G, Boero E, Sverzellati N, Cardinale L, Busso M, Boccuzzi F, et al. Semi-quantification of pneumothorax volume by lung ultrasound. Intensive Care Med. 2014;40:1460-7.

6. Gargani L, Volpicelli G. How I do it: lung ultrasound. Cardiovasc Ultrasound. 2014; $12: 25$.

7. Volpicelli G, Melniker LA, Cardinale L, Lamorte A, Frascisco MF. Lung ultrasound in diagnosing and monitoring pulmonary interstitial fluid. Radiol Med. 2013:118:196-205.

8. Vitale V, Ricci Z, Gaddi S, Testa G, Toma P, Cogo P. Lung ultrasound profile after cardiopulmonary bypass in paediatric cardiac surgery: first experience in a simple cohort. Interact Cardiovasc Thorac Surg. 2017;24:598-602.

9. Cantinotti M, Giordano R, Valverde I. Lung ultrasound: a new basic, easy, multifunction imaging diagnostic tool in children undergoing pediatric cardiac surgery. J Thorac Dis. 2017;9:1396-9.

10. Cantinotti M, Giordano R, Assanta N, Murzi B, Gargani L. Chest ultrasound: a new, easy, and radiation-free tool to detect retrosternal clot after pediatric cardiac surgery. J Cardiothorac Vasc Anesth. 2015;29:e59-60.

11. Cantinotti M, Giordano R, Corana G, Franchi E, Koestenberger M, Kutty S. Use of linear and convex ultrasound transducers for evaluation of retrosternal area in patients after cardiac surgery. Echocardiography. 2018;35:100-3. 